\title{
SOME ASPECTS OF LOWER AND MIDDLE VOLGA POPULATION INTERACTION
} IN NEOLITHIC AGE

(C)2014
K.M. Andreev, graduate student of the Department of Russian History and Archeology

Samara State Academy of Social Sciences and Humanities, Samara (Russia)

Annotation: The article analyses the problem of different Neolitization origins in specified regions. In early Neolithic Age the contacts had a small coverage. Wide-ranging penetration of Lower Volga pin- scratched pottery ornamentation tradition carriers into forest steppe refers to VI and V centuries BC. It was caused by natural and climatic reasons. Up to the late Neolithic Age the influence was one-way - from south to north.

Keywords: Lower Povolzhye; forest-steppe Povolzhye; Neolithic age; elshanskaya culture; middle Volga culture; archeological pottery; flinty manufacture.

УДК 902.03

\section{К ВОПРОСУ О СПЕЦИФИКЕ КОНТЕКСТА РАСПОЛОЖЕНИЯ СТОЯНКИ КАМЕННОГО ВЕКА «БАЙБЕК»}

(C) 2014

Н.П. Антимонов, ведущий инженер-конструктор,

Федеральное государственное унитарное предприятие Государственный научно-производственный ракетно-космический центр «ЦСКБ-ПРОГРЕСС» (ФГУП ГНПРКЦ «ЦСКБ-Прогресс»), Самара (Россия)

Аннотаџия. В статье рассматривается практика выявления погребенных объектов по космическим снимкам, полученным с помощью космического аппарата «Landsat-8».

Ключевые слова. Дистанционное зондирование; поиск погребенных объектов; археология.

В основу исследования специфики контекста но сделать заключение о специфике контекста располорасположения стоянки каменного века «Байбек» Красноярского района Астраханской области положены:

- находки, сделанные археологами в полевой сезон 2013 г. на неолитической стоянке «Байбек», в виде костных останков некоторых пород пресноводных рыб;

- предположение о том, что слои осадочных пород различного геологического (гидрогеологического) периода должны иметь различный «отклик» в спектральных диапазонах потока отраженного излучения от земной поверхности.

Исходя из существующих фактов и принятых предположений была определена целевая задача тематического дешифрирования материалов дистанционного зондирования Земли (ДЗ3) и выбран алгоритм выполнения камеральных работ для достижения цели.

В качестве материалов, позволяющих получить требуемые доказательства и наиболее соответствующих поставленной задаче, были выбраны и использованы материалы Д33 с космического аппарата (КА) «Landsat-8», обработка которых осуществлялась в среде программного пакета ENVI 4.5.

В ходе предварительной обработки материалов Д33 и синтеза изображений по цветной структуре RGB был определён набор спектральных каналов, позволяющих получить решение тематической задачи. Результатом этого процесса стало синтезированное изображение, в котором спектральные каналы съемки 11, 10 и 7 КА «Landsat-8» были расположены по структуре RGB (см. рисунок 1).

Результат тематического дешифрирования отражен на рисунке 2.

Извилистая линия на общем фоне изображения показывает примерное расположение береговой линии Каспийского моря в период неолита.

Звездочка указывает место расположения стоянки «Байбек».

На основании полученных результатов тематического дешифрирования, а также отметок относительных высот поверхности земли в районе стоянки «Байбек» можжения стоянки каменного века «Байбек» Красноярского района Астраханской области.

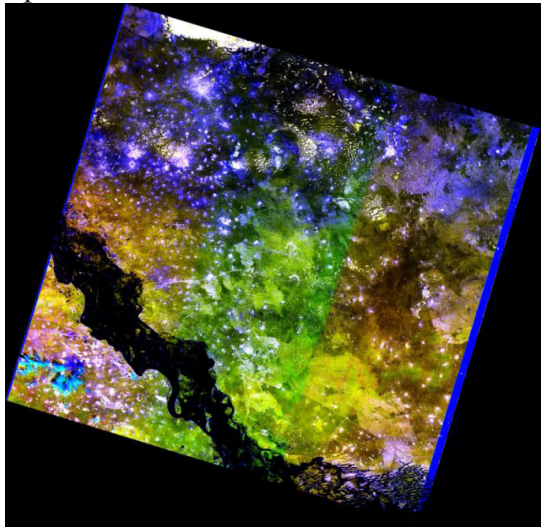

Рис. 1. Снимок синтезированного изображения, полученного с помошью КА по схеме каналов 11-10-7

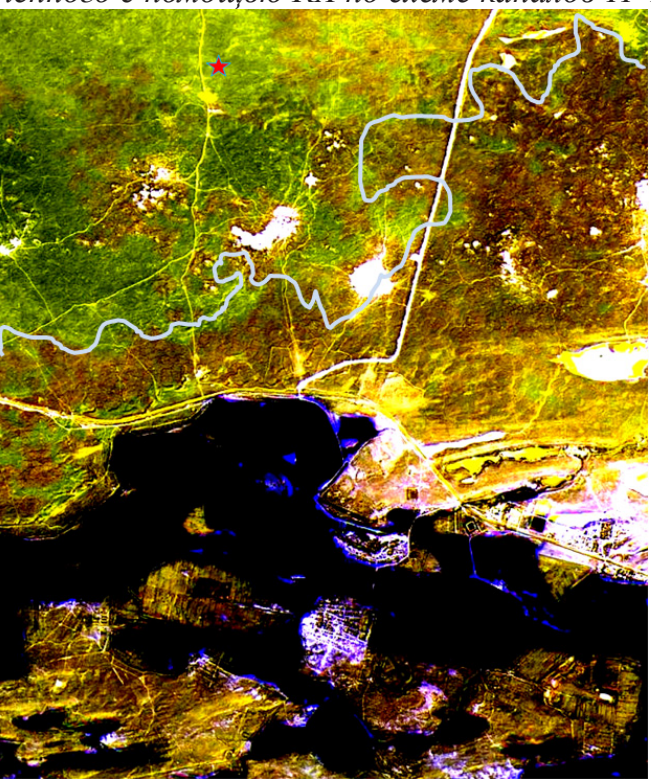

Рис. 2. Возможная граница уровня Каспийского моря в период существования стоянки «Байбек» 
В период существования стоянки «Байбек» (период неолита) береговая зона Каспийского моря, в соответствии со второй стадией новокаспийской трансгрессии, находилась в непосредственной близости от стоянки. Неолитическая стоянка могла находиться практически в береговой зоне. Это подтверждается явно выраженной окраской фото-тона на фрагменте космического снимка, сделанного в тепловом инфракрасном спектральном диапазоне (см. рисунок 2), который создает примерную картину уреза стояния вод Каспийского моря в тот период.
Это подтверждается также общей картиной абсолютных отметок окружающего стоянку ландшафта, которая показывает, что поднятие вод Каспия даже до отметки -22 м переводит территорию стоянки в прибрежную зону [1].

\section{СПИСОК ЛИТЕРАТУРЫ}

1. Отчет по тематическому дешифрированию. «Специфика контекста расположения стоянки каменного века «Байбек» Красноярского района Астраханской области по данным «Landsat-8» и «ЕО-1»». ГНПРКЦ «ЦСКБ - Прогресс», Самара, 2014, 61c.

\title{
(C) 2014
}

\section{THE QUESTION OF CONTEXT SPECIFIC LOCATION STONE AGE "BAIBEK"}

\section{N.P. Antimonov, lead engineer-designer}

Federal state unitary enterprise State research-andproduction space centre "CSKB-PROGRESS", Samara (Russia)

Annotation: Practice of buried objects detection on satellite images obtained from spacecraft "Landsat- 8 " is considered. Keywords: Remote sensing; searching of buried objects; archaeology.

\section{УДК 902.6}

О СООТНОШЕНИИ ПАМЯТНИКОВ КАИРШАКСКОГО И ТЕНТЕКСОРСКОГО ТИПОВ (C) 2014

\author{
A.B. Барацков, аспирант кафедры отечественной истории и археологии \\ Поволжсккая государственная сочиально-гуманитарная академия, Самара (Россия)
}

Аннотащия: На основании новых данных и тщательной проработке исследованного материала автор аргументирует тезис, что памятники каиршакского и тентексорского типов являются последовательными этапами одной культуры, подтверждая предположение А.А. Выборнова.

Ключевые слова. Нижнее Поволжье; Северный Прикаспий; неолит; каиршакско-тентексорская культура; археологическая керамика; кремневая индустрия.

До сих пор среди ученых нет единого мнения о том, являются ли памятники каиршакского и тентексорского типов последовательными этапами одной культуры или они представляют собой разные культурные образования.

По всей вероятности, аридизация климата, случившаяся в интервале 7500-7200 л.н. [1; 2], стала причиной миграции части каиршакского населения на север. Количество неолитических памятников по сравнению с предыдущим и последующим интервалами сокращается, культурные слои редки и маломощны, а количество находок незначительно, следовательно, население покидало как крупные стоянки, так и менее заселенные. По мнению В.В. Ставицкого, это придало определенный импульс развитию памятников типа Варфоломеевки и Джангара и привело к распространению прочерченнонакольчатой традиции украшения керамики. В дальнейшем происходит ее эволюция: уменьшается удельный вес прочерченного орнамента, который сокращается до $11 \%$ на сосудах верхнего слоя Варфоломеевской стоянки и сходит на нет на поселении Тентексор. Кроме возрастания роли накольчатого орнамента, на варфоломеевской керамике наблюдается появление ряда сложных узоров, которые отсутствуют на Каиршаке III, но являются характерными для Тентексора. Это состоящие из наколов прямоугольники, фигуры, напоминающие песочные часы, горизонтальные зигзаги, шевроны, вписанные друг в друга ромбы [3, с. 206]. В верхнем слое Варфоломеевки уменьшается количество сосудов с наплывом на венчике, которые на Тентексоре представлены единичными экземплярами (4,5\%). Примерно равную долю в посуде этих комплексов занимают профилированные сосуды $(24 \%$ и $20 \%)$. По пути сближения с тентексорской развивается и каменная индустрия Варфоломеевской и Джангарской стоянок. На основании этих выводов В.В. Ставицкий считает, что джангарско-варфоломеевские древности не только заполняют хронологический пробел между памятниками каиршакского и тентексорского типов, но и иллюстрируют процесс трансформации одних традиций в другие.

Исследователи отмечают значительный хронологический разрыв между развитым каиршакским и поздним тентексорским этапами местного неолита $[4 ; 5 ; 6 ; 7]$. Тем не менее на территории Северного Прикаспия были обнаружены небольшие, но очень интересные комплексы, которые могли бы претендовать на более раннюю хронологическую позицию, чем материалы стоянок Тентексор и Жеколган. Одним из таких памятников является стоянка Качкарстау [8, с. 87]. Культурный слой памятника полностью разрушен эоловой эрозией. Однако обнаруженные на поверхности артефакты располагались на ограниченной площади, и какой-либо планиграфической локализации кремневых изделий от фрагментов керамики не прослеживалось $[8$, с. 88$]$.

Керамика стоянки изготавливалась из илистого сырья с примесью ракушки. Орнамент наносился крупными наколами подпрямоугольной или овальной формы в отступающей манере, резными линиями, аморфными ямочными вдавлениями. Несмотря на ограниченность коллекции (17 фрагментов), можно сделать ряд замечаний.

Для тентексорской посуды характерна обильная примесь раковины. Насечки и пальцевые вдавления по срезам, а также наличие наплывов у венчиков сближает фрагменты Качкарстау с поздненеолитическими. Крупные наколы в отступающей манере характерны именно для тентексорских комплексов. Таким образом, керамический набор стоянки Качкарстау сближается с поздненеолитическими. Однако кремневый инвентарь этой стоянки архаичнее, чем тентексорский. Сырье неоднородно, преобладающим является: непрозрачный белесый халцедон и полупрозрачный халцедон различных оттенков от серого до синеватого [8, с. 89]. Такое сырье характерно для памятников развитого неолита - стоянок Каиршак I - IV [9, с. 106]. Характер заготовок для изготовления орудий позволяет сделать следующие выводы.

По наличию крупных пластинчатых сколов данная коллекция сближается с материалами тентексорского типа. Прием получения крупных пластин ударом еще не сформировался окончательно, что еще раз указывает на более архаичную технологию, чем тентексорская. Самарский научный вестник. 2014. № 3(8) 